\title{
TUBAL TRANSPORT AND FERTILIZATION OF OVA IN GONADOTROPHIN-TREATED PIGS
}

\author{
J. L. HANCOCK* AND H. L. BUTTLE $\dagger$ \\ A.R.C., Animal Breeding Research Organisation, Edinburgh 9
}

(Received 26th Fuly 1967)

\begin{abstract}
Summary. Untreated sows and sows injected with human chorionic gonadotrophin (HCG) 2 or 3 days after removal of the litter were inseminated into the oviducts. All of eleven untreated sows yielded blastocysts (5.2 blastocysts/sow) at autopsy 7 to 10 days later. Five of twenty-five HCG-treated sows yielded a total of thirteen blastocysts.

The results are described of experiments designed to examine more closely the effects of HCG treatment.

It is shown that the small number of embryos recoverable after tubal insemination of HCG-treated sows cannot be explained by failure of fertilization.

Surgical recovery of eggs was less successful in HCG-treated sows than in untreated sows.

The sites of recovery of eggs were studied in treated and untreated sows examined at autopsy at varying intervals after ovulation. Eggs were found in the oviducts of HCG-treated sows up to $104 \mathrm{hr}$ after ovulation; by this time all eggs had reached the uterus in untreated sows.
\end{abstract}

\section{INTRODUCTION}

The precise control of the time of ovulation in pigs treated with human chorionic gonadotrophin (Dziuk \& Baker, 1962; Buttle \& Hancock, 1967) makes it possible to specify the age of the ovum relative to mating or insemination, provided that one can exclude spontaneous ovulations which might occur at a time unrelated to the time of treatment with gonadotrophin. This condition can largely be met if sows are injected on the 2nd day after removal of the litter. In the experiments to be described below, sows were injected with gonadotrophin on the 2nd or 3rd day after removal of the litter so that ovulation (which occurs approximately $40 \mathrm{hr}$ after injection of gonadotrophin) would occur on the 4th or 5th day after weaning, i.e. 1 or 2 days before the normally expected time. With this procedure it was found that when HGG-treated sows were inseminated into the oviducts only a few sows yielded blastocysts when examined 7 to 10 days after insemination and very few blastocysts were recovered from individual sows. By contrast, most untreated sows yielded blastocysts although the number per sow was low. Two further series of experiments are described which were designed to seek an explanation for these findings. In the first series

* Present address: Royal Veterinary College, Royal College Street, London, N.W.1.

† Present address: National Institute for Research in Dairying, Shinfield, Reading. 
treated and inseminated sows were again inseminated into the Fallopian tube and surgical recovery of eggs was attempted on the day following insemination for examination for evidence of fertilization. No evidence was found that the chances of fertilization were lower in HCG-treated sows than in untreated sows, but recovery of ova was less successful in treated sows and there was evidence that recovery was impaired by the insemination treatments. Attempts to identify more clearly the effects of insemination on subsequent recovery were unsuccessful.

The second series of experiments was undertaken to compare the success of recovery at autopsy of ova in HCG-treated and untreated sows, i.e. without the comblicatina effects of suraical intervention. Recoverv was more successful in untreated than in treated sows, and the comparison of the sites of recovered ova between treated and untreated sows showed that transport of ova to the uterus is delayed by HCG treatment.

\section{MATERIALS AND METHODS}

The source of animals and the procedures used for the detection of oestrus and for the recovery and examination of ova have already been described (Hancock, 1958a, b; Hancock \& Hovell, 1962; Buttle \& Hancock, 1967). Trials for heat were made at approximately 09.00 hours and 17.00 hours. The day of onset of oestrus is here referred to as Day 0. Treated sows received 500 i.u. HGG ('Lutormope'-Burroughs Wellcome \& Co.) intravenously or intramuscularly on Day 2W (Day $0_{w}$ here means the day of removal of the litter). The time of ovulation in Gonadotrophin-treated pigs was taken to be $40 \mathrm{hr}$ after injection of HCG. Insemination into the Fallopian tube was done at laparotomy into the ovarian or luterine end; inseminations into the ovarian end were made with a $1 \mathrm{ml}$ glass pipette irsserted to a depth of not less than $1 \mathrm{~cm}$. For irrsemnination into tire uterine end, a 1-in. hypodermic needle (23 s.w.g.) was passed through the wall of the uterus about $1 \mathrm{~cm}$ posterior to the tubo-uterine junction or its antimesometrial border and inserted into the oviduct through the tubo-uterine junction. Semen was injected from an attached 1-ml syringe.

When treatments differed between the two oviducts, one side was marked at the time of operation with a ligature placed in the uterine broad ligament ofthat side. This was done to eliminate any possible errors of identification of the two oviducts at successive laparotomies.

The standard insemination dose was $0-2 \mathrm{ml}$ sperm-rich fraction of fresh semen diluted 1:3 with Tyrode's solution containing $1 \mathrm{mg} / \mathrm{ml}$ bovine serum albumin with added streptomycin $(50 \mu \mathrm{g} / \mathrm{ml})$ and penicillin $(50 \mathrm{i} . \mathrm{u} . / \mathrm{ml})$. Semen was stored for up to $2 \mathrm{hr}$ undiluted after collection, until needed, and diluted immediately before insemination.

Data regarding the recovery of ova were discarded in cases where the Fallopian tube was ruptured during flushing or when some of the flushings were lost from other causes. The decision to discard data was made before any search for eggs had been made. For statistical analysis, the percentage of recovered eggs after angular transformation was used after weighting for the number of eggs shed. Analysis of variance was made on the transformed weighted data. 
RESULTS

Recovery of blastocysts after tubal insemination of untreated and HCG-treated sows

Table 1 summarizes the results of inseminations of twenty-five gonadotrophin-treated and eleven untreated sows which were examined at autopsy 7 to 10 days after insemination. Untreated sows were inseminated approximately 24 $\mathrm{hr}$ after the onset of oestrus; HCG-treated sows were inseminated 36 to $53 \mathrm{hr}$ after injection. All of eleven untreated sows yielded blastocysts compared with only five of twenty-five treated sows. The mean number of blastocysts per sow (5.2) is clear evidence that normal fertility was not obtained by tubal insemination even in the untreated group. In the treated group, of a total of 390 eggs shed, only eight were represented as blastocysts.

TABLE 1

THE NUMBER OF BLASTOGYSTS RECOVERED FROM HGG-TREATED AND UNTREATED SOWS AFTER INSEMINATION INTO THE OVARIAN END OF THE FALLOPIAN TUBE

\begin{tabular}{|c|c|c|c|c|c|c|}
\hline \multirow{2}{*}{$\begin{array}{c}\text { Dose of } \\
H C G(i . u .)\end{array}$} & \multirow{2}{*}{$\begin{array}{c}\text { Time of injection } \\
\text { of HCG } \\
\text { (days after weaning) }\end{array}$} & \multirow{2}{*}{$\begin{array}{c}\text { Sows } \\
\text { inseminated }\end{array}$} & \multirow{2}{*}{$\begin{array}{l}\text { Fertile } \\
\text { sows* }\end{array}$} & \multirow{2}{*}{$\begin{array}{c}\text { Eggs shed } \\
\text { (corpora lutea) }\end{array}$} & \multicolumn{2}{|c|}{ Eggs recovered } \\
\hline & & & & & $\begin{array}{l}\text { Blastocysts } \\
\text { No. \% }{ }^{\circ}\end{array}$ & $\begin{array}{c}\text { Unfertilized eggs } \\
\text { No. }\end{array}$ \\
\hline $\begin{array}{l}\text { None } \\
500 \\
500\end{array}$ & $\overline{2}$ & $\begin{array}{r}11 \\
19 \\
6\end{array}$ & $\begin{array}{r}11 \\
4 \\
1\end{array}$ & $\begin{array}{r}182 \\
316 \\
74\end{array}$ & $\begin{array}{r}31 \\
2 \\
3\end{array}$ & $\begin{array}{l}3 \\
8 \\
0\end{array}$ \\
\hline
\end{tabular}

* Sows yielding blastocysts.

$\dagger \%$ of eggs shed that are represented by blastocysts.

Examination of the results for untreated sows, which were found at laparotomy at the time of insemination already to have ovulated and those which had not ovulated, showed no evidence that fertility was affected by the time of insemination relative to ovulation. Four untreated sows which had already ovulated when inseminated yielded a total of nineteen blastocysts. Seven untreated sows which ovulated after insemination yielded thirty-eight blastocysts. Of the sows treated on Day $2_{w}$, ten had ovulated at the time of insemination and two yielded blastocysts; of eight which were inseminated before ovulation, blastocysts were recovered from one. Data regarding the occurrence of ovulation are lacking for the remaining sow.

The failure to recover blastocysts or eggs at 7 to 12 days after tubal insemination of HCG-treated sows could be due to:

(a) Failure of fertilization and failure to find unfertilized eggs.

(b) Loss of fertilized eggs from the reproductive tract.

(c) Death of fertilized embryos and failure to find the degenerate embryos.

Further experiments were designed to attempt to isolate the source of the apparent low fertility.

Surgical recovery of ova from $H C G$-treated and untreated sows

Sixteen sows were allocated at random to two groups-HGG-treated and untreated. All sows were inseminated into one oviduct only and eggs were 
recovered surgically $24 \mathrm{hr}$ later from both oviducts. The findings are summarized in Table 2. The striking feature of the data is the low recovery rate (fourteen of fifty-seven eggs shed) from the inseminated tubes of HCG-treated sows; eggs were recovered from only four of eight tubes in this group; all other tubes yielded some eggs. Analysis shows that differences between tubes of treated sows are highly significant $(P<0.001)$. Differences between inseminated and control tubes are also significant for untreated sows $(P<0 \cdot 05)$. There are also differences due to HGG treatment of sows both for inseminated $(P<0.01)$ and for control tubes $(P<0 \cdot 05)$. The findings furnish evidence of an effect of both gonadotrophin treatment and of tubal insemination on the recovery of ova.

TABLE 2

THE NUMBERS OF EGGS RECOVERED AND FERTILIZED FROM HCG-TREATED AND UNTREATED SOWS WHICH WERE INSEMINATED VIA ONE FALLOPIAN TUBE

\begin{tabular}{l|c|l|c|c|c|c|c}
\hline \multirow{2}{*}{$\begin{array}{c}\text { Treatment } \\
\text { of sow }\end{array}$} & $\begin{array}{c}\text { No. of } \\
\text { tubes }\end{array}$ & $\begin{array}{c}\text { Treatment } \\
\text { of tube }\end{array}$ & $\begin{array}{c}\text { Tubes yielding } \\
\text { eggs }\end{array}$ & \multicolumn{4}{|c}{ Eggs } \\
\hline None & 16 & None & 8 & 54 & 53 & 57 & 1 \\
& 16 & Inseminated & 8 & 58 & 46 & 39 & 25 \\
HCG & 16 & None & 8 & 74 & 65 & 58 & 0 \\
& & Inseminated & 4 & 57 & 14 & 14 & 13 \\
\hline
\end{tabular}

* Includes eggs from some horns not included for calculation of recovery rates (see text).

Thirty-nine eggs from inseminated horns of untreated sows were classifiable after fixation and staining; of these twenty-five were fertilized but nine were judged to be abnormal. Of fourteen eggs recovered from the inseminated tubes of HCG-treated sows, thirteen were fertilized, two being abnormal. The small number of blastocysts recovered from untreated sows inseminated into the oviduct in the last experiment could, therefore, have been due to a low fertilization rate, but the findings on HCG-treated sows suggest that failure of fertilization was not the cause of the low yield of blastocysts from treated sows inseminated into the Fallopian tube.

It is of interest that, with the possible exception of one egg, no spermatozoa were found on eggs recovered from uninseminated tubes and none was fertilized (the exceptional egg could have been carried over accidentally when the same catheter was used to collect eggs from both inseminated and control horns: subsequently precautions were taken to eliminate this possibility). Apparently transport of spermatozoa from the inseminated to the uninseminated tube is unlikely to occur.

\section{Factors affecting surgical recovery of ova after tubal insemination}

A factorial experiment was designed to examine the effect on recovery of ova of: (a) site of insemination (ovarian end versus uterine end of oviduct), (b) time of insemination relative to ovulation (at the approximate time of ovulation versus approximately $12 \mathrm{hr}$ before ovulation), and (c) time of injection of gonadotrophin ( 2 days after weaning versus 3 days after weaning). Fourteen sows (twenty-eight tubes) were allocated at random to the eight treatment 
groups. Sows for insemination at the time of ovulation were inseminated 41 to $43 \mathrm{hr}$ after injection of gonadotrophin; sows for insemination approximately 12 $\mathrm{hr}$ before ovulation were inseminated 26 to $30 \mathrm{hr}$ after injection. Eggs were recovered surgically approximately $24 \mathrm{hr}$ after ovulation. The findings provided no clear evidence that recovery rate is determined by any one of these variables. In this experiment, of forty-seven eggs examined after fixation and staining, thirty were judged to be fertilized but eight of these were judged to be abnormal, two being obviously polyspermic.

A further experiment was designed to examine other factors in tubal insemination which might affect recovery of ova. All sows received 500 i.u. HGG intravenously on Day $2_{w}$. Inseminations were made into the ovarian end of the oviducts 41 to $44 \mathrm{hr}$ after the injection with HCG. Four treatments were used: (a) insemination of undiluted semen, (b) insemination of Tyrode's solution only, (c) blank insemination-this procedure involved placing momentarily a dry, sterile $1.0 \mathrm{ml}$ insemination pipette into the ovarian end of the oviduct, and (d) the uterine horn and Fallopian tube were left undisturbed in the abdominal cavity. Two treatments per sow were used at random, one to each oviduct on a total of eighteen sows. Recovery rates for the four classes were: (a) $36.5 \%$, (b) $62.6 \%$, (c) $61.7 \%$, and (d) $48.9 \%$. Analysis of variance showed that these differences were not significant. The marked loss of eggs from the untouched control horns (only forty-five eggs recovered of ninety-two eggs shed) is in contrast to the previous findings (Table 2, sixty-five eggs recovered of seventyfour eggs shed). Formal statistical analysis is complicated because of the heterogeneity within the data from the more recent experiment, but using the FisherBehrens-Sukhatme test (Fisher \& Yates, 1953) the differences between the two sets of data were found by our colleague, Mr A. F. Purser, to be statistically significant $(P=0 \cdot 05)$. The gonadotrophin treatment, anaesthetic and surgical procedures were the same for both experiments; the only notable difference between the animals in the two experiments is in parity. In the first experiment all had had one litter; in the second experiment they had had two.

\section{Recovery of eggs at autopsy from HCG-treated and untreated sowes}

In view of the variable results it was decided to examine at autopsy the effect of HGG on the recovery of eggs from sows not exposed to surgical treatments. Estimates of the time of ovulation of untreated sows are based on the assumption that ovulation occurs $36 \mathrm{hr}$ after the onset of oestrus. Untreated and HCGtreated sows were killed and examined at varying intervals after the expected time of ovulation. Autopsies of sows at 09.00 hours on Day 4 are recorded as having been made 60 to $76 \mathrm{hr}$ after ovulation in the case of sows first showing heat in the morning (96 to $112 \mathrm{hr}$ after the onset of heat) or 52 to $60 \mathrm{hr}$ after ovulation in the case of sows first showing heat at the afternoon trial (88 to $96 \mathrm{hr}$ after the onset of heat).

All of thirteen sows injected with HCG intravenously yielded eggs at recovery 3 days later (25 hr after ovulation); of a total of 204 eggs shed, $146(71.6 \%)$ eggs were recovered. All of seventeen sows injected with HCG intramuscularly yielded eggs at recovery 3 days later; of a total of 286 eggs shed, $186(65.0 \%)$ eggs were recovered. In both groups of sows all eggs were recovered from the oviducts. 
Table 3 shows the number of eggs shed and recovered and the site of recovered ova, for contemporary batches of untreated and treated sows killed at varying intervals from 25 to $106 \mathrm{hr}$ after ovulation.

The percentage of eggs recovered is seen to be consistently lower for HCGtreated sows than for untreated sows. It is also shown that in untreated sows the proportion of eggs in the Fallopian tube declines with time after ovulation so that virtually all recovered eggs are in the uterus of untreated sows examined more than $76 \mathrm{hr}$ after ovulation. In contrast, a considerable proportion $(30.8 \%)$ of eggs recovered from HCG-treated sows, killed as late as $104 \mathrm{hr}$ after ovulation, was found in the oviducts.

TABLE 3

THE NUMBER OF EGGS FOUND IN THE FALLOPIAN TUBES OF UNTREATED AND HCG-TREATED SOWS KILLED AT VARYING INTERVALS AFTER OVULATION*

\begin{tabular}{|c|c|c|c|c|c|}
\hline \multirow{2}{*}{$\begin{array}{l}\text { Time of examination } \\
\text { (hr after ovulation })^{*}\end{array}$} & \multirow{2}{*}{$\begin{array}{l}\text { Eggs } \\
\text { shed }\end{array}$} & \multicolumn{2}{|c|}{ Eggs recovered } & \multicolumn{2}{|c|}{ Tubal eggs } \\
\hline & & No. & $\%$ & No. & $\%$ \\
\hline $\begin{array}{l}\text { Untreated } \\
36 \text { to } 52 \\
52 \text { to } 60 \\
60 \text { to } 76 \\
76 \text { to } 84 \\
84 \text { to } 100\end{array}$ & $\begin{array}{c}179(12) \\
75(4) \\
493(43) \\
100(6) \\
54(3)\end{array}$ & $\begin{array}{r}138 \\
55 \\
396 \\
84 \\
44\end{array}$ & $\begin{array}{l}77 \cdot 0 \\
73 \cdot 3 \\
80 \cdot 3 \\
84 \cdot 0 \\
81 \cdot 4\end{array}$ & $\begin{array}{r}136 \\
37 \\
95 \\
2 \\
0\end{array}$ & $\begin{array}{c}98 \cdot 5 \\
67 \cdot 3 \\
23 \cdot 9 \\
2 \cdot 4 \\
0\end{array}$ \\
\hline $\begin{array}{c}\text { HCG-treated } \\
25 \\
49 \\
72 \\
80 \\
104\end{array}$ & $\begin{array}{l}490(30) \\
102(6) \\
408(23) \\
725(37) \\
288(16)\end{array}$ & $\begin{array}{r}332 \\
62 \\
271 \\
480 \\
201\end{array}$ & $\begin{array}{l}67 \cdot 7 \\
60 \cdot 8 \\
66 \cdot 4 \\
66 \cdot 2 \\
69 \cdot 7\end{array}$ & $\begin{array}{r}332 \\
62 \\
112 \\
205 \\
52\end{array}$ & $\begin{array}{l}100 \\
100 \\
41 \cdot 3 \\
42 \cdot 7 \\
30 \cdot 8\end{array}$ \\
\hline
\end{tabular}

* Time of ovulation in untreated sows is taken to be $36 \mathrm{hr}$ after the onset of heat. In HCG-treated sows it is taken to be $40 \mathrm{hr}$ after the injection of gonadotrophin.

Table 4 shows the distribution of sows according to the site of recovery of eggs. It shows that only one of nine untreated sows had any tubal eggs at autopsy more than $76 \mathrm{hr}$ after ovulation; whereas twelve of sixteen treated sows killed $104 \mathrm{hr}$ after ovulation had some tubal eggs and three had all eggs still in the oviducts.

The finding of tubal eggs up to $104 \mathrm{hr}$ after injection might be due to a second crop of ovulations which may or may not be related to the HCG treatment. Counts of corpora lutea and of large follicles were made in the ovaries of two groups of sows killed, respectively, 2 and 6 days after gonadotrophin injection ( $8 \mathrm{hr}$ and $104 \mathrm{hr}$ after the prescribed time of ovulation). The mean numbers of corpora lutea in the two groups were 17.5 (8 hr group) and $17.3(104 \mathrm{hr}$ group); the mean numbers of follicles were 3.8 and $4 \cdot 8$. There is no evidence here either of an increase in the numbers of corpora lutea or of a decrease in the numbers of follicles with time after injection; there is, therefore, no evidence for the occurrence of delayed ovulation (in this group of sows killed $104 \mathrm{hr}$ 
after ovulation, twenty-three of eighty-two recovered eggs $(28 \%)$ were found in the oviducts).

Tubal and uterine eggs were fixed and stained separately from fourteen sows, killed 80 to $104 \mathrm{hr}$ after injection. Of fifty-three tubal eggs, thirty-six were visibly fragmented. Normal metaphase figures were visible in none. Of

TABLE 4

THE CLASSIFICATION OF UNTREATED AND HCG-TREATED SOWS ACGORDING TO THE SITE (IN OVIDUGTS ONLY, IN BOTH OVIDUCTS AND UTERUS OR IN UTERUS ONLY) OF OVA RECOVERED AT AUTOPSY AT VARYING INTERVALS AFTER OVULATION*

\begin{tabular}{|c|c|c|c|c|c|}
\hline \multirow{2}{*}{$\begin{array}{l}\text { Time of } \\
\text { examination (hr } \\
\left.\text { after ovulation }{ }^{*}\right)\end{array}$} & \multirow{2}{*}{$\begin{array}{l}\text { Total } \\
\text { sowess }\end{array}$} & \multicolumn{3}{|c|}{ Site of recovered eggs } & \multirow{2}{*}{$\begin{array}{c}\text { Sows } \\
\text { yielding } \\
\text { no eggs }\end{array}$} \\
\hline & & Oviducts & $\begin{array}{c}\text { Oviducts } \\
\text { and uterus }\end{array}$ & Uterus & \\
\hline $\begin{array}{c}\text { Untreated } \\
36 \text { to } 52 \\
52 \text { to } 60 \\
60 \text { to } 76 \\
76 \text { to } 84 \\
84 \text { to } 100\end{array}$ & $\begin{array}{r}12 \\
4 \\
43 \\
6 \\
3\end{array}$ & $\begin{array}{r}12 \\
1 \\
6 \\
0 \\
0\end{array}$ & $\begin{array}{r}0 \\
3 \\
16 \\
1 \\
0\end{array}$ & $\begin{array}{r}0 \\
0 \\
21 \\
5 \\
3\end{array}$ & $\begin{array}{l}- \\
\overline{-} \\
\overline{-}\end{array}$ \\
\hline $\begin{array}{l}\text { HCG-treated } \\
25 \\
49 \\
72 \\
80 \\
104\end{array}$ & $\begin{array}{r}30 \\
6 \\
23 \\
37 \\
16\end{array}$ & $\begin{array}{r}30 \\
5 \\
6 \\
6 \\
3\end{array}$ & $\begin{array}{r}0 \\
0 \\
14 \\
22 \\
9\end{array}$ & $\begin{array}{l}0 \\
0 \\
2 \\
8 \\
3\end{array}$ & $\begin{array}{l}\overline{1} \\
1 \\
1 \\
1\end{array}$ \\
\hline
\end{tabular}

* The time of ovulation in untreated sows is taken to be $36 \mathrm{hr}$ after the onset of heat. In HCG-treated sows it is taken to be $40 \mathrm{hr}$ after the injection of gonadotrophin.

TABLE 5

THE SITE OF RECOVERY OF EGGS FROM MATED AND UNMATED UNTREATED SOWS

\begin{tabular}{c|c|c|c}
\hline \multirow{2}{*}{ Sows } & \multicolumn{3}{|c}{ Site of recovered eggs } \\
\cline { 2 - 4 } & Oviducts & $\begin{array}{c}\text { Oviducts } \\
\text { and } \\
\text { uterus }\end{array}$ & Uterus \\
\hline Mated* & 1 & 7 & 13 \\
Unmated & 4 & 4 & 5 \\
\hline
\end{tabular}

* All matings were to vasectomized boars.

sixty-two uterine eggs, forty-eight were visibly fragmented and all lacked normal metaphase figures. On this evidence there is no reason to believe that the time of ovulation of the tubal eggs was later than that of the uterine eggs.

The finding of eggs in the oviducts of untreated sows as late as the 4th day after the onset of heat was unexpected. Because not all sows were actually served by the boar at the time of trial it was possible to compare mated and unmated sows as regards the site of recovery of eggs. The findings are summarized 
in Table 5. There is some suggestion that transport of ova was slower in unmated sows than in mated sows.

\section{DISCUSSION}

The observations recorded here suggest that the explanation of the low fertility of untreated sows inseminated into the oviduct could be failure of fertilization. The results show that the low fertility of tubal inseminations of HCG-treated sows cannot be explained on these grounds. The more likely explanation of the low fertility of HGG-treated sows seems to be disturbed transport of ova. The finding that ova may be found in the oviducts of HCG-treated sows up to 104 $\mathrm{hr}$ after ovulation provides convincing evidence of disturbed tubal activity; the evidence here being that, in untreated sows, all eggs have normally entered the uterus at this time. However, the findings suggest that entry of eggs into the uterus may be delayed considerably beyond the time recorded by Pomeroy (1955); Oxenreider \& Day (1965) have also recorded finding tubal eggs occasionally as late as 90 to $108 \mathrm{hr}$ after the onset of oestrus and it may be there are breed differences in the speed of transport of pig eggs or that the interval between the onset of oestrus and ovulation is inconstant. It may be important to note that the findings in the present experiments refer exclusively to unfertilized eggs recovered from unmated pigs or from pigs mated to vasectomized boars. Differences between fertilized and unfertilized eggs or between mated and unmated sows could, therefore, be responsible for the differences between previous findings, which refer to sows mated to fertile boars, and those recorded here. Evidence is lacking about the first possibility; the evidence here as regards the effect of mating is inconclusive but is sufficient to justify further investigation. In neither of the previous investigations referred to is there any suggestion that some pigs may have both tubal and uterine eggs although this was a not uncommon finding here. The findings on the time of exit from the oviduct of eggs shed by spontaneously ovulating untreated sows are not critical because of failure to identify more precisely the time of onset of heat. However, the absence of more precise information does not invalidate the observed difference between treated and untreated pigs in the time of entry of eggs into the uterus. The assumption was made that the interval between the onset of heat and ovulation is as short as $36 \mathrm{hr}$ (Burger, 1952); if the interval is longer or shorter than this, the interval between ovulation and entry of eggs into the uterus must be reduced or increased accordingly.

Disturbed tubal transport might prejudice fertility in more than one way. Eggs could be lost from the reproductive tract either by upward displacement into the abdominal cavity or by expulsion via the vagina; the evidence here is against the latter possibility. Development of eggs may also be prejudiced by retention within the Fallopian tube beyond the normal time; there is considerable experimental evidence to show that the entry of eggs into the uterus must be synchronous with a particular stage of uterine development for successful implantation to occur. It may be that delayed tubal transport of ova is a source of some of the known loss of pig embryos in untreated sows; whether or not this is the case, it could certainly be responsible for some of the impaired 
fertility of gonadotrophin-treated pigs which has been reported by other workers (Dziuk \& Polge, 1962; Radford, 1965).

It is difficult to interpret the variability of the results in different experiments and in particular it is difficult to know what weight to attach to the earlier finding that losses of ova were more likely to occur in the inseminated tube of HCG-treated pigs than in the non-inseminated tube. Certainly, in the experiments designed to examine the various possibilities, no evidence was found to enable one to discriminate between mechanical effects of insemination or of chemical constituents of the semen or of the diluent, which might conceivably have affected egg transport.

It seems important to try to identify the mode of action whereby HGG treatment affects egg transport. There is no information to suggest that HCG has a direct action on tubal motility. It seems more likely that the explanation of the observed effects lies in the artificial situation whereby eggs are shed into a presumably pro-oestrous genital tract. In these experiments, eggs were shed either on the 4th or 5th day after weaning (depending upon the day of HGG injection) whereas untreated sows would normally be in heat at this time and would not normally ovulate before the 5th or 6th day. It was shown previously (Buttle \& Hancock, 1967) that HCG injection frequently prevents the occurrence of oestrus at the normal period and it is a matter for speculation what is the physiological status at the time of ovulation of the sow injected with HCG 2 or 3 days after weaning. Can the inhibition of oestrus by HCG treatment be taken as evidence of precocious termination of the oestrogenic phase and of the induction of a precocious progestational phase? Or is it possible that HGG treatment results in eggs being shed into a tract still sensitized to oestrogen?

The available evidence is against the view that delayed tubal transport might be due to progesterone. In general, progesterone has been found to hasten the transport of ova from the tubes to the uterus although Chang (1966) has shown that the effects of progesterone depend to some extent on the time of its administration relative to ovulation, and Adams (1965) has shown that the transport of rabbit eggs to the uterus is accelerated by reducing the number of corpora lutea.

It is now well established that administered oestrogen may result in delayed or accelerated tubal transport depending upon dosage and duration and time of treatment (Burdick \& Pincus, 1935; Whitney \& Burdick, 1936; Pincus \& Kirsch, 1936). The failure of transport of ova in HCG-treated sows could therefore be due to oestrogen: the evidence in these experiments is that accelerated transport never occurred and that any loss of eggs from the tract probably resulted from upward displacement of eggs into the peritoneal cavity; the findings of Whitney \& Burdick (1936) led them to conclude that this occurred in oestrogen-treated mice and Noyes, Adams \& Walton (1959) concluded that similar losses were the explanation for their failure to recover eggs transferred to oestrogen-treated rabbits.

\section{AGKNOWLEDGMENTS}

We are grateful to Moira Rennie for technical assistance and to Alastair MacGregor for supervision of the animals. 


\section{REFERENCES}

ADAMs, C. E. (1965) Enucleation of early corpora lutea in the rabbit. F. Endocr. 32, 395.

Burdick, H. O. \& Pincus, G. (1935) The effect of oestrin injections upon the developing ova of mice and rabbits. Am. F. Physiol. 111, 201.

Burger, J. F. (1952) Sex physiology of pigs. Onderstepoort 7. vet. Res. Suppl. 2.

ButtLe, H. L. \& Hancock, J. L. (1967) Control of ovulation in the sow. F. Reprod. Fert. 14, 485.

Chang, M. G. (1966) Effect of oral administration of medroxy progesterone acetate and ethinyl estradiol on the transportation and development of rabbit eggs. Endocrinology, 79, 939.

Dziuk, P. J. \& BAKER, R. D. (1962) Induction and control of ovulation in swine. F. Anim. Sci. 21, 697.

Dzruk, P. J. \& Polge, C. (1962) Fertility in swine after induced ovulation. F. Reprod. Fert. 4, 207.

Fisher, R. A. \& YATES, F. (1953) Statistical tables for biological, agricultural and medical research. Oliver \& Boyd, Edinburgh.

Hancock, J. L. (1958a) The fertility of natural and of artificial matings in the pig. Stud. Fert. 9, 146.

HANCOCK, J. L. (1958b) The examination of pig ova. Vet. Rec. 70, 1200.

Hancock, J. L. \& Hoveld, G. J. R. (1962) Egg transfer in the sow. 7. Reprod. Fert. 4, 195.

Noyes, R. W., Adams, C. E. \& Walton, A. (1959) The transport of ova in relation to the dosage of oestrogen in ovariectomized rabbits. F. Endocr. 18, 108.

Oxenreider, S. L. \& DAy, B. N. (1965) Transport and cleavage of ova in swine. F. Anim. Sci. 24, 413.

Prscus, G. \& KIRsch, R. E. (1936) The sterility in rabbits produced by injections of oestrone and related compounds. Am. F. Physiol. 115, 219.

Pomeroy, R. W. (1955) Ovulation and the passage of ova through the fallopian tubes in the pig. F. agric. Sci., Camb. 45, 327.

RAdFord, P. (1965) Synchronization of ovulation in sows at the first post-weaning ocstrus. Vet. Rec. 77, 239.

WhITNEY, R. \& Burdick, H. O. (1936) Tube-locking of ova by oestrogenic substances. Endocrinology, 20,643. 